\title{
A Lagrangian perspective of the tropopause and the ventilation of the lowermost stratosphere
}

\author{
G. Berthet, ${ }^{1,2}$ J. G. Esler, ${ }^{3}$ and P. H. Haynes ${ }^{1}$ \\ Received 29 November 2006; revised 11 May 2007; accepted 29 May 2007; published 18 September 2007.
}

[1] Back trajectories driven by large-scale analyzed wind fields are used to investigate troposphere to stratosphere transport (TST) in the Northern Hemisphere tropopause region, as well as the surface sources for such transport, defined in terms of the locations where each trajectory last left the atmospheric boundary layer (log pressure height $z_{*}<1 \mathrm{~km}$ ). The proportion $\chi_{\mathrm{BL}}$ of those trajectories arriving in the tropopause region that have visited the boundary layer within the previous fixed time period (typically 30 days) is determined as a function of each trajectory's final equivalent latitude and potential temperature. For a range of potential temperature surfaces $(\sim 300-380 \mathrm{~K}), \chi_{\mathrm{BL}}$ is shown to have a sharp gradient in the extratropics indicative of a partial permeable barrier to transport that can be identified as a "Lagrangian tropopause." Variations in $\chi_{\mathrm{BL}}$ with equivalent latitude and potential temperature and on seasonal timescales are shown to provide a novel measure for the relative location and permeability of the tropopause barrier. Details such as the presence of a "ventilated layer" in the northern summer extratropical lower stratosphere $(\sim 370-410 \mathrm{~K})$ are clearly apparent. Directly below this layer $(340-370 \mathrm{~K})$ the tropopause barrier to transport is shown to be relatively strong, whereas below $340 \mathrm{~K}$ it is again more permeable. A distinction can therefore be made between "extratropical" TST that primarily ventilates the lowermost stratosphere below $340 \mathrm{~K}$ and "tropical" TST that occurs into the 370-410 K ventilated layer. The boundary layer source regions for extratropical TST are shown to correspond to those regions previously identified as sources for deep frontal uplift in the warm conveyor belt circulations of extratropical cyclones, although elevated regions such as the Himalayan plateau are also seen to be important. Tropical TST has different source regions associated with regions of active deep convection such as the western tropical Pacific and, in the northern summer, the Indian subcontinent. The source regions are, in general, found to be geographically localized, leading to the conclusion that subject to the limitations of the methodology, trace gas emissions in specific regions are substantially more likely to be transported to the lowermost stratosphere than elsewhere. The implications for the assessment of ozone depletion by very short lived halogenated species are mentioned.

Citation: Berthet, G., J. G. Esler, and P. H. Haynes (2007), A Lagrangian perspective of the tropopause and the ventilation of the lowermost stratosphere, J. Geophys. Res., 112, D18102, doi:10.1029/2006JD008295.

\section{Introduction}

[2] The tropopause region is seen as key for understanding and predicting future chemical-climate change. This is because changes in concentrations of radiatively active species in this region potentially have a strong effect on the radiation balance of the troposphere [e.g., Forster and Shine, 1997] and because this region plays an important role

\footnotetext{
${ }^{1}$ Centre for Atmospheric Science, Department of Applied Mathematics and Theoretical Physics, University of Cambridge, Cambridge, UK.

${ }^{2}$ Now at Laboratoire de Physique et Chimie de l'Environnement, CNRS, Orleans, France.

${ }^{3}$ Department of Mathematics, University College London, London, UK.

Copyright 2007 by the American Geophysical Union. 0148-0227/07/2006JD008295
}

in determining the chemical composition of the stratosphere with implications for ozone [e.g., Ko et al., 2003].

[3] Historically, the tropopause has been regarded as a control surface, and most attention has focused on the net flux of ozone and other species across this surface, with these net fluxes being controlled by global-scale processes as part of the Brewer-Dobson circulation [Holton et al., 1995]. However, as observations and models provide a more detailed description of the tropopause region, there is now more emphasis on two-way transport across the tropopause, both troposphere to stratosphere transport (TST) and stratosphere to troposphere transport (STT), with the difference between these being the net exchange. This emphasis on two-way transport is particularly important in the extratropics, where there is significant interest in the tropospheric influence on the chemical composition of the extratropical lowermost stratosphere (LMS), i.e., the region 
above the tropopause but below a suitably chosen isentropic surface (usually the $380 \mathrm{~K}$ surface) corresponding roughly to the tropopause in the tropics. Part of this interest arises from the need to assess the role of relatively short-lived halocarbon species ("very short lived species" (VSLS)) [Bridgeman et al., 2000; Dvortsov et al., 1999; Ko et al., 2003] in ozone destruction.

[4] The interest in two-way transport has also been stimulated by in situ chemical measurements that show clear indications of air of recent tropospheric origin in the LMS [e.g., Ray et al., 1999]. In particular, one aspect revealed by recent measurements is that a layer immediately above the extratropical tropopause exhibits chemical characteristics intermediate between the extratropical troposphere and the stratosphere, for example, in species such as ozone, carbon monoxide $(\mathrm{CO})$, reactive nitrogen $\left(\mathrm{NO}_{y}\right)$, and water [Hoor et al., 2002; Fischer et al., 2000; Hoor et al., 2004; Pan et al., 2004; Krebsbach et al., 2006]. This layer may be referred to as the extratropical tropopause layer (ExTL). The upper limit of the ExTL has been estimated from enhanced $\mathrm{CO}$ and $\mathrm{H}_{2} \mathrm{O}$ mixing ratios to be about $25 \mathrm{~K}$ in potential temperature (or to extend about $2-3 \mathrm{~km}$ in height above the local tropopause defined by the 2 potential vorticity unit (PVU) surface) or by the World Meteorological Organization definition based on vertical temperature gradient.

[5] An aspect of tropospheric influence on the LMS is that above the ExTL, there is evidence from various chemical species, including water vapor, $\mathrm{CO}$, and $\mathrm{CO}_{2}$, that a substantial proportion of the air in the LMS has moved quasi-horizontally from the upper tropical troposphere [Dessler et al., 1995; Hintsa et al., 1998; Ray et al., 1999; Pan et al., 2000; Hoor et al., 2005], rather than descending from the stratospheric "overworld." There is, in the Northern Hemisphere (NH) at least, significant seasonal variation in this fraction [Ray et al., 1999; Pan et al., 2000], which is argued to be around $60 \%$ in the summer and autumn and closer to $30 \%$ in the winter and spring [Hoor et al., 2005].

[6] A distinction between, on the one hand, transport into the LMS from the extratropical troposphere (with the effects of the this transport confined in height to the ExTL) and, on the other hand, transport from the tropical upper troposphere has some justification from transport diagnostics. It appears that at all seasons the maximum of the subtropical jet acts as an effective barrier to transport between troposphere and stratosphere, with more quasi-horizontal transport above (from the tropical upper troposphere) and below (from the extratropical troposphere). This is seen, for example, in the height-latitude variation of effective diffusivity shown by Haynes and Shuckburgh [2000]. The effective diffusivity also shows the strong seasonal variation of transport, with a much weaker barrier in the NH summer.

[7] Trajectory studies, using three-dimensional winds from meteorological data sets, have been widely used to study the two-way transport between troposphere and stratosphere, e.g., in the Influence of Stratosphere-Troposphere Exchange in a Changing Climate on Atmospheric Transport and Oxidation Capacity (STACCATO) project as summarized by Stohl et al. [2003]. Quantifying this two-way transport has several subtleties, as discussed by Stohl [2001] and Wernli and Bourqui [2002], for example. One approach is described by James et al. [2003a] in which a single ensemble of trajectories was integrated over a long period, but each trajectory had a corresponding set of "clocks" that was reset according to certain criterion, such as crossing the tropopause (with the latter defined by a potential vorticity (PV) based criterion). This allows diagnosis of fields such as "age of stratospheric air in the troposphere" and "age of tropospheric air in the stratosphere," as shown in Figures 1 and 10, respectively, of James et al. [2003b]. A different approach is described by Wernli and Bourqui [2002] and Sprenger and Wernli [2003] in which a set of trajectories are initialized and followed for a finite time and those trajectories that obey a certain transport criterion, specifically that the tropopause is crossed and that the trajectory remains on one side of the tropopause for a certain time, are identified. This allows, for example, identification of deep TST and STT events, defined to occur when a trajectory crosses the $700 \mathrm{hPa}$ surface and the PV $=2 \mathrm{PVU}$ tropopause within 4 days; geographical identification of source regions for such events; and calculation of TST and STT fluxes, including fluxes conditioned on certain categories of transport event.

[8] Notwithstanding the important contribution of the studies just mentioned, there is as yet no consensus on a "best" measure of quantifying transport, and indeed different measures will certainly be more or less relevant to different chemical species. For example, the chemical influence of VSLS on the LMS will be especially sensitive to the details of the transport pathways of stratospheretroposphere exchange. This sensitivity is due first to the fact that because of the relatively short lifetime of the VSLS a direct pathway must exist from the chemical source regions to the LMS, otherwise chemical decay and mixing will prevent the VSLS reaching the LMS with significant concentration. A second consideration is the strong vertical gradient in certain chemical species within the LMS itself; for example, ozone concentrations in the extratropics can increase from approximately $100 \mathrm{ppbv}$ in the upper troposphere to $>1000$ ppbv only 6-7 km higher. Unsurprisingly, therefore modeling studies [e.g., Salawitch et al., 2005] indicate that the efficiency with which bromine-containing VSLS (suspected of enhancing the amount of inorganic bromine $\mathrm{Br}_{y}$ at the tropopause level and in the lower stratosphere) contribute to the catalytic destruction of ozone is a strong function of height. Because of these considerations, for the case of the VSLS, inferences drawn from a relatively crude measure such a mass flux across a control surface may be extremely misleading.

[9] In this paper we present a different trajectory-based quantification of transport based on large ensembles of back trajectories from a grid of points distributed evenly in longitude and latitude. Our particular focus is on whether those trajectories visit certain regions, in particular, the boundary layer and the tropics. We concentrate on back trajectories that originate in the upper troposphere/lower stratosphere (UTLS) region and find it convenient to group such trajectories according to their final (in the sense of forward time) potential temperature and equivalent latitude, with the latter defined by potential vorticity on an isentropic surface. A key quantity derived from the trajectories is then the proportion for a given equivalent latitude and potential temperature that has visited, for example, the boundary 
layer. We proceed under an assumption of relatively rapid longitudinal homogenization within the UTLS and hence do not regard it as important, for example, to analyze the longitudinal structure of the statistics of tropopause crossing, since wherever trajectories cross the tropopause, they will subsequently be rapidly dispersed in longitude.

[10] A key aspect of longitudinal variation that we do examine is the variation of the regions in the boundary layer that are visited by trajectories originating in the LMS in backward time. These are source regions for the LMS, and the nature of chemical sources in those regions will presumably have a strong effect on the chemical nature of the LMS. In developing a "climatology" of these source regions, as well as demonstrating how they depend upon the arrival potential temperature level in the LMS, we aim to give detailed insight into the transport pathways by which chemical species may reach the LMS. A measure of the "density" of particles leaving the boundary layer allows the importance of different regions of emission to be compared quantitatively, although uncertainties necessarily remain in regards to the extent to which parcels will retain their chemical characteristics as they are transported to the LMS.

[11] The calculations show, not surprisingly, that trajectories originating in the LMS have a small probability of reaching the boundary layer in a given time, whereas those in the troposphere have a much larger probability. The variation of this probability with potential temperature and equivalent latitude naturally maps out the extratropical tropopause. We compare with standard PV-based definitions of the tropopause, and we argue that the probability of visiting the boundary layer in backward time is itself a rather fundamental measure of the distinction between troposphere and stratosphere and can therefore itself be used as a useful definition of the tropopause. The smooth variation of the probability field in the $290-320 \mathrm{~K}$ region is seen to be consistent with the observed presence of the ExTL.

[12] The trajectory calculations do not by themselves address the question of whether air in the tropopause region is a genuine mixture of air with tropospheric and stratospheric properties or whether there are distinct air masses in this region with those properties. However, several other authors [e.g., Stohl, 2001] have pointed out the strong stirring that occurs in the tropopause region and the fact that air masses brought into this region are rapidly drawn out into filamentary structures that will be vulnerable to any later mixing processes. Therefore we do not attempt to address this issue further in this paper. Another key issue for the interpretation of our results, discussed in detail in section 2.2 , is that in using trajectories driven by large-scale winds from the European Centre for Medium-Range Weather Forecasts (ECMWF) analyzes, not all relevant transport processes will be captured. In particular, the calculated trajectories will not accurately capture the range of timescales for transport of air parcels from the tropical boundary layer to the tropical tropopause layer, where deep convection occurs in cumulonimbus clouds on scales considerably below that resolved by the ECMWF winds. We believe, however, that our important conclusions remain at least qualitatively independent of this limitation, principally because the limiting transport processes determining trans- port into the LMS, and hence our results are large-scale and quasi-isentropic.

[13] In section 2 we describe the trajectory calculations and the methodology used to process the information from the trajectories. In section 3 we move on to describe the results, focusing on the latitude-height structure of transport that is revealed and on its seasonal variation. In section 4 we discuss the longitudinal variations of the "source" regions mentioned above, and in section 5 we present our conclusions.

\section{Methodology}

\subsection{Model, Data and Method}

[14] We perform three-dimensional trajectory integrations using a trajectory code [Methven, 1997]. In this model, three-dimensional off-line meteorological data (such as velocity, temperature, and humidity) are interpolated to the trajectory locations (or particle positions) using bilinear interpolation in time and in the horizontal and cubic Lagrange interpolation in the vertical. Trajectories are then integrated using a fourth-order Runge-Kutta scheme. Values of meteorological fields (e.g., PV, surface pressure, and temperature) are assigned as attributes for the particles for each integration time. Further details, including accuracy tests, are given by Methven [1997]. In our study the trajectory model is driven on 60 ECMWF model levels with the three-dimensional ECMWF operational analysis winds, temperature, and ground pressure available daily at the four analysis times $(0000,0600,1200$, and $1800 \mathrm{UT})$, for which the trajectory positions and physical properties (pressure, temperature, potential temperature, and potential vorticity) are stored. For the 2002-2005 period considered in this study we use operational analysis winds spectrally truncated to the T159 spectral resolution and archived by the British Atmospheric Data Centre (http://badc.nerc.ac.uk/ home/). The surface data for the T159 resolution are provided on a nonregular N80 (N80 refers to 80 latitudinal grid points in each hemisphere) reduced Gaussian grid. Note that vertical transport in the stratosphere has been found to be better represented in the operational analysis compared with, for example, the ERA-40 reanalysis [e.g., Meijer et al., 2004].

[15] Thirty day backward trajectories are initialized at 0000 UT from grid points covering the Northern Hemisphere and are evenly spaced in latitude and longitude and in potential temperature (the choice of the 30 day duration is discussed in section 2.3). Information from the back trajectories is processed by first grouping trajectories according to their initial equivalent latitude $\phi_{e}$ and potential temperature $\theta$. Equivalent latitude is defined with respect to potential vorticity on an isentropic surface, following Butchart and Remsberg [1986]. Since in inviscid adiabatic flow air parcels conserve $\phi_{e}$ and $\theta$, equivalent latitude potential temperature coordinates are chosen to best characterize chemical air masses, following, e.g., Hegglin et al. [2005], and hence reversible (e.g., wave-like) transport has no effect in this coordinate system. For comparison, results were also plotted as a function of latitude and potential temperature $(\phi, \theta)$ and equivalent latitude and pressure $\left(\phi_{e}, p\right)$. In the former case, results were found to be "smoothed" somewhat in the latitudinal direction, as 
might be expected as a consequence of zonal averages being taken across the tropopause region. In the latter case, there was no noticeable difference in results to report. Note that in adopting $\left(\phi_{e}, \theta\right)$ coordinates an implicit assumption is being made that longitudinal variations of air mass characteristics in the UTLS region are relatively weak (and largely captured by any longitudinal variations of the potential vorticity field associated with longitudinal structure in the large-scale circulation). It is assumed that in the UTLS the timescale since an air parcel has left the boundary layer (in which there are certainly strong longitudinal inhomogeneities in chemical sources) is relatively long compared to the timescale for longitudinal homogenization by the large-scale flow.

[16] A key diagnostic to be employed is the proportion $\chi_{R}$ of trajectories to have visited a specified region $R$ during the 30 day backward integration. The quantity $\chi_{R}$ is calculated as a function of $\left(\phi_{e}, \theta\right)$ by "binning" trajectories according to their arrival $\phi_{e}$ on each $\theta$ level. We concentrate on two main choices of the specified region $R$ : (1) The boundary layer, defined as the region with log-pressure height $z_{*}=$ $H \log \left(p_{s} / p\right)<1 \mathrm{~km}$, where $p$ is pressure, $p_{s}$ is surface pressure, and $H=8 \mathrm{~km}$ is a constant scale height, defines the proportion $\chi_{\mathrm{BL}}$. (2) The tropics, defined as latitudes southward of the $10^{\circ} \mathrm{N}$ latitude circle, define the proportion $\chi_{10}$.

[17] In order to investigate the trajectory source regions in the boundary layer a density function $\rho_{\theta}(\lambda, \phi)$ is defined, for each $\theta$ level, as a function of longitude $\lambda$ and latitude $\phi$ as follows. On the potential temperature $\theta$ level under consideration those trajectories that are "stratospheric" at the back trajectory arrival time $t=0$ are selected. Following, for example, Holton et al. [1995], the lower of the 2 PVU $\left(1 \mathrm{PVU}=10^{-6} \mathrm{~m}^{2} \mathrm{~s}^{-1} \mathrm{~K} \mathrm{~kg}^{-1}\right)$ and $380 \mathrm{~K}$ surfaces is used to define the tropopause, although the sensitivity to this definition is discussed in section 3 . The selected trajectories are then examined to see if they have visited the boundary layer at any time during the previous 30 days. If so, the longitude and latitude where the trajectory most recently left the boundary layer are recorded and used to build up the density field $\rho_{\theta}(\lambda, \phi)$ by adding a unit to the appropriate longitude-latitude "bin." In order to generate a wellresolved picture the process is repeated for trajectory start dates at bimonthly intervals for the entire period of the investigation. Results are then averaged for the northern winter (DJF), spring (MAM), summer (JJA), and autumn (SON) seasons. This allows the longitude-latitude bins to be chosen to be sufficiently small $\left(5^{\circ} \times 5^{\circ}\right)$ to create a wellresolved density field. For a given $\theta$ level, during the whole period under consideration, those trajectories that have visited the boundary layer at some stage and have stratospheric PV ( $>2$ PVU) at the trajectory arrival time are selected. On the basis of the total number $N(\theta)$ of such trajectories the expected contribution from each $5^{\circ} \times 5^{\circ}$ region of the boundary layer is calculated under the assumption that the $N(\theta)$ particles are equally likely to originate from anywhere on the globe, without any seasonal variation. This results in a latitude-dependent factor that is used to normalize the number of trajectories that is actually found to originate from each region in the calculations. By design, therefore, $\rho_{\theta}$ is a measure of the relative importance, and seasonal variability, of different geographical regions as sources for trajectory transport from the boundary layer to a given $\theta$ level in the stratosphere.

[18] For the purposes shown in section 3, two main starting grid resolutions were employed for the trajectories in the UTLS: a high-resolution grid $\left(1^{\circ} \times 1^{\circ} \times 5 \mathrm{~K}\right.$, with 30 vertical levels from 290 to $435 \mathrm{~K}$ ) and a low-resolution grid $\left(2.5^{\circ} \times 2^{\circ} \times 30 \mathrm{~K}\right.$, with 4 vertical levels from 305 to $395 \mathrm{~K})$. The high-resolution grid $(982,800$ trajectories) was used to produce several individual snapshots of the situation at the UTLS and, as discussed in section 2.3, appears to be sufficient to generate relatively smooth, converged results for $\chi_{\mathrm{BL}}\left(\phi_{e}, \theta\right)$ and $\chi_{10}\left(\phi_{e}, \theta\right)$. The medium-resolution grid (26,496 trajectories) was used to generate the multiannual runs using bimonthly start dates for the back trajectories. These runs were used to investigate the seasonal variations in the transport characteristics to the UTLS and to generate converged fields for $\rho_{\theta}(\lambda, \phi)$. The multiannual runs cover the period December 2001 to July 2005. Note that other grid resolutions are utilized in the sensitivity tests described below.

\subsection{Limitations of Trajectory Studies Based on Analyzed Winds}

[19] As discussed in section 1, there is considerable uncertainty about the extent to which trajectories driven by analyzed winds can represent physical transport processes in the atmosphere, principally because of the effects of unresolved motions and mixing events. The STACCATO project [Stohl et al., 2003] has emphasized the important role of subsynoptic-scale features, such as warm conveyor belts and stratospheric intrusions (these are believed to be well resolved by the analyzed velocity fields). What is much less certain is the extent to which the analyzed velocity fields capture the effects of convection. Stohl [2001] has argued that the effects of midlatitude frontal convection, including warm conveyor belts, are well captured. Regions of large-scale tropical convection, such as the Intertropical Convergence Zone (ITCZ), are also present in the analyzed winds. However, as pointed out by James et al. [2003a] and Fueglistaler et al. [2004], vertical motions associated with individual convective cells, which clearly occur on subgrid scales with respect to the analyzed winds, cannot be resolved. James et al. [2003a] implemented a stochastic parameterization of transport because of subgrid, deep, convective cells in their Lagrangian particle model (FLEXPART) to investigate this issue. Consistent with the discussion above, a relatively small effect was found in the extratropics, but a more significant effect was found in the tropics.

[20] A particular, related issue, which is relevant to the current study, is the extent of (subgrid) convective penetration into the LMS itself. The extent of the role of subgrid convection in extratropical stratosphere-troposphere exchange is at present unclear, and, of course, trajectory studies provide a useful quantitative diagnostic only under the assumption that most of that exchange is associated with the large-scale flow rather than subgrid processes. With regard to the extratropics, there are in situ chemical measurements that point very clearly to convective injection of tropospheric air into the stratosphere [e.g., Poulida et al., 1996; Fischer et al., 2003], while other measurements have given no direct evidence of penetration of extratropical 
convection into the stratosphere [Ridley et al., 2004]. There are also studies that combine chemical measurements with meteorological or trajectory studies that argue for such convection [e.g., Hegglin et al., 2004]. Dessler and Sherwood [2004] argue that convective penetration to the $380 \mathrm{~K}$ surface in midlatitudes, while much less frequent than in the tropics, is nevertheless sufficient to have a significant effect on water vapor at these altitudes, although not on ozone (since the relative difference in ozone concentrations between troposphere and stratosphere is much smaller than the relative difference in water vapor concentrations). It is possible then that such convection is mainly important for trace gases with active sources in North America during the summer, as much of the extratropical convective activity occurs there [Dessler and Sherwood, 2004]. Fu et al. [2006] have recently shown that convective injection of boundary layer air into the stratosphere may also occur over and near the Himalayan plateau in the northern summer. It therefore needs to be kept in mind that convective-scale processes not resolved by trajectories may play a direct role in TST or STT. Such processes may be represented using, e.g., stochastic methods [James et al., 2003a]; however, because of the difficulties associated with validating such approaches we have decided not to include them for the present.

[21] In addition to the above, there are further numerical issues associated with the limited temporal (6 hour) and vertical $(\sim 0.5 \mathrm{~km})$ resolution of the analyzed winds used to drive the trajectories [Wernli and Bourqui, 2002; Fueglistaler et al., 2004; Bourqui, 2006]. One key effect of limited resolution is likely to be increased cross- isentropic dispersion of trajectories, as calculated heating rates become noisier because of sampling and interpolation errors.

[22] To summarize, it is worth repeating the remark of Fueglistaler et al. [2004] that an extremely conservative interpretation of our results is that they apply to "ECMWF world" rather than the real atmosphere. Even if this view is taken, ECMWF world merits study because of the extensive use of analyzed winds to drive chemistry transport models. Eulerian chemistry transport models are necessarily more diffusive than the atmosphere, even at high resolutions, and hence trajectory studies provide a useful and complementary nondiffusive picture of the transport processes occurring in models. The extent to which the same picture is relevant to the atmosphere is likely to be a topic for ongoing debate.

\subsection{Sensitivity Studies}

[23] Various parameters have been used to set our trajectory calculations, for example, trajectory start dates, duration of integration, and grid resolution. The sensitivity of the obtained $\chi_{R}$ fields to variations to these parameters has been carefully assessed, including the sensitivity to the definition of the region $R$ itself.

[24] First, the sensitivity to the precise date chosen for the initialization of the back trajectories was examined. The use of equivalent latitude and potential temperature as coordinates might be expected to significantly reduce the sensitivity of $\chi_{R}$ to particular meteorological events, and also $\chi_{R}$ is determined not simply by the velocity fields on the day of initialization but by the time history of the velocity fields over the duration of the back trajectory prior to the day of initialization. It might be expected that there is no acute sensitivity to the initialization date. This was verified explicitly by repeating the integrations for nearby initialization dates. The results gave confidence that the distribution of $\chi_{R}$ was robust to changes in initialization date.

[25] A second important practical point concerns the time length of the back trajectories chosen to emphasize characteristics of transport from the two different regions $R$. To verify the relevance of the 30 day trajectory length used in the calculations in sections 3 and 4, otherwise identical calculations were repeated with trajectory lengths of 60 days and 15 days, respectively. In both cases the distribution of the contours of constant $\chi_{R}\left(\phi_{e}, \theta\right)$ remains largely unaltered, although the absolute values of $\chi_{R}\left(\phi_{e}, \theta\right)$ change. In Figure 1 an example of the change in $\chi_{R}\left(\phi_{e}, \theta\right)$ with changing trajectory length can be seen directly. Figure 1a shows a scatterplot of $\chi_{\mathrm{BL}}\left(\phi_{e}, \theta\right)$ for 31 July 2002 with the calculated 60 day trajectory values plotted against the 30 day values. The fact that the scatterplot relationship is compact verifies that the structure of the contours of constant $\chi_{\mathrm{BL}}\left(\phi_{e}, \theta\right)$ is robust under the trajectory length change. As expected, however, the values of $\chi_{\mathrm{BL}}$ are significantly higher for the 60 day trajectory lengths. Figure $1 \mathrm{~b}$ shows a scatterplot with the 15 day trajectory length results plotted against the 30 day results. Again, the relationship is fairly compact but less so than for the 60-30 day case. The increased scatter reflects the fact that few particles reach the upper LMS within 15 days, and as a result, the $\chi_{\mathrm{BL}}$ contours in the 15 day case do differ a little from the 30 day case in the upper LMS region, where the results are also affected by noise. Overall, however, the qualitative results below are found to be remarkably robust to trajectory length changes within the above range. Another point of concern is the spacing of the initialization grid needed to give a robust, smoothly varying field $\chi_{R}$. Results from grid resolutions of $1^{\circ} \times 1^{\circ}, 2^{\circ} \times 2^{\circ}, 3^{\circ} \times 3^{\circ}$, and $4^{\circ} \times 4^{\circ}$ were compared, and it was found that near identical, although increasingly noisy, $\chi_{R}$ fields were obtained. The low- $\left(2.5^{\circ} \times 2^{\circ} \times 30 \mathrm{~K}\right)$ and high- $\left(1^{\circ} \times 1^{\circ} \times 5 \mathrm{~K}\right)$ resolution grids discussed above were therefore chosen for the main investigation described in sections 3 and 4.

[26] A further issue is the sensitivity to the definition of the dynamical tropopause as a surface of constant PV. Previous studies [e.g., Dethof et al., 2000] have shown that calculated results for TST are relatively insensitive to the value of PV chosen for the tropopause in the range of 2-5 PVU, although some geographical details of the calculated transport may change [Pan et al., 2000]. The sensitivity of the calculated $\rho_{\theta}$ fields defined above to the value of PV taken used to determine entry into the stratosphere have been tested by repeating the calculations for PV values of 1, 2, 3, and 4 PVU. The geographical distribution of $\rho_{\theta}$ was found not to vary under these changes; hence a value of 2 PVU was selected for the calculations reported in sections 3 and 4 .

[27] Finally, the importance of the precise definition of the chosen regions $R$ was assessed. No qualitative differences in results were obtained when the boundary layer definition was changed either to $z_{*}=0.5 \mathrm{~km}$ or to $z_{*}=2 \mathrm{~km}$. Further, the field $\chi_{10}$ obtained as a measure of transport to 

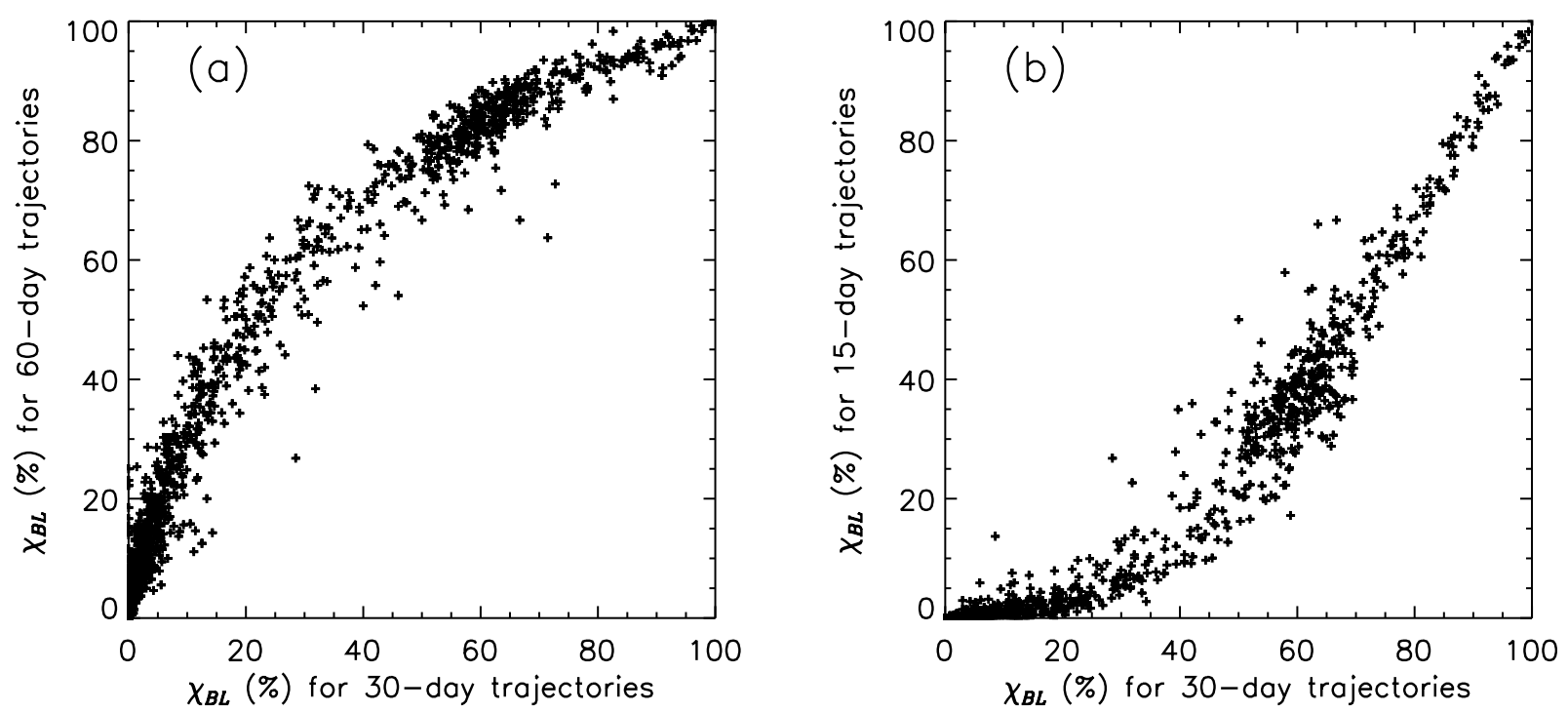

Figure 1. Scatterplot of $\chi_{\mathrm{BL}}\left(\phi_{e}, \theta\right)$ for 31 July 2002 calculated for (a) 60 day back trajectory lengths plotted against 30 day back trajectory lengths and (b) 15 day back trajectory lengths plotted against 30 day back trajectory lengths. Points are plotted for $0<\phi_{e}<85^{\circ} \mathrm{N}$ at $2^{\circ}$ intervals and for $290<\theta<420 \mathrm{~K}$ at $5 \mathrm{~K}$ intervals.

the tropics was found to be largely unaltered by extending the region $R$ northward to $20^{\circ} \mathrm{N}$.

\section{Results}

\subsection{Transport Barrier at the Tropopause}

[28] Results from the trajectory sets arriving on the highresolution grid at 0000 UT on 31 January 2003 and 0000 UT on 31 July 2002 will be examined. Figure 2 shows a snapshot of the proportion field $\chi_{\mathrm{BL}}\left(\phi_{e}, \theta\right)$, defined in section 2.1, i.e, the proportion of trajectories arriving on the grid, which have seen the boundary layer during the previous 30 days. Note the nonlinearity of the color scale, which has been designed to enable differences in $\chi_{\mathrm{BL}}$ within the relatively isolated LMS region to be resolved. Figure 2a shows the northern winter (start date 31 January 2003) results, and Figure $2 \mathrm{~b}$ shows the northern summer (start date 31 July 2002) results. In both the summer and winter the most striking feature is a sharp latitudinal gradient in $\chi_{\mathrm{BL}}$, which is present at all levels above the $310 \mathrm{~K}$ isentropic surface and moves equatorward with increasing potential temperature. The location of this latitudinal jump in $\chi_{\mathrm{BL}}$ can be considered to define a "Lagrangian tropopause," as it marks a boundary or transport barrier separating an air mass that is in regular contact with the surface (i.e., the troposphere) and an air mass, that is relatively isolated (i.e., the lowermost stratosphere (LMS)). The $\chi_{\mathrm{BL}}$ field in Figure 2 confirms that the transport barrier associated with the tropopause is relatively weak below $310 \mathrm{~K}$, consistent with the absence of any strong signature of the tropopause in effective diffusivity calculated from isentropic winds at these levels [Haynes and Shuckburgh, 2000].

[29] The use of an objective tropopause definition, determined by transport characteristics, has clear advantages for transport calculations compared with empirically chosen control surfaces (e.g., PV $=2$ PVU and 100 ppbv ozone). Spurious and reversible two-way transport effects may dominate fluxes across a control surface in locations where the surface does not coincide with the dynamical mixing barrier to isentropic transport associated with the tropopause. Other techniques, such as effective diffusivity calculations [Haynes and Shuckburgh, 2000], have previously been successfully used to identify the location of the tropopause mixing barrier. However, Figure 2 shows that the current method not only resolves the mixing barrier clearly but also suggests that a definition of the tropopause based on a constant value of $\chi_{\mathrm{BL}}$ (e.g., $\chi_{\mathrm{BL}}=20 \%$ (black curve)) acts as reasonable definition for both the winter and summer. This definition has the advantages of both being relatively intuitive, straightforward to calculate, and able to be closely associated with a quantitative, well-resolved picture of the location and seasonal variation in the mixing barrier's strength. In a vertical layer centered around $\chi_{\mathrm{BL}}=$ $20 \%$ the value of $\chi_{\mathrm{BL}}$ falls rapidly from $\gtrsim 40 \%$ to around $2 \%$, consistent with a "mixing layer" or extratropical tropopause layer with chemical characteristics intermediate between the troposphere and the LMS proper [Fischer et al., 2000; Hoor et al., 2004; Pan et al., 2004]. The vertical extent of the ExTL defined by this criterion is about $15 \mathrm{~K}$ in potential temperature, i.e., apparently comparable to typical thicknesses suggested on the basis of trace gas measurements by Hoor et al. [2005].

[30] In both the summer and winter the contours of $\chi_{\mathrm{BL}}$ in Figure 2 can be seen to follow approximately the contours of potential vorticity (white curves), although the correspondence is far from exact. In particular, Figure 2 shows that in winter, there is a significant region in high latitudes with PV $>2$ PVU within the isentropic layer 290-310 K that has relatively high values of $\chi_{\mathrm{BL}}(\geq 10 \%)$ compared to the remainder of the LMS above and hence is ventilated relatively rapidly by troposphere air. The contribution from this 290-310 K layer to calculations of mass fluxes across a tropopause defined by the PV $=2$ PVU surface may lead to an 

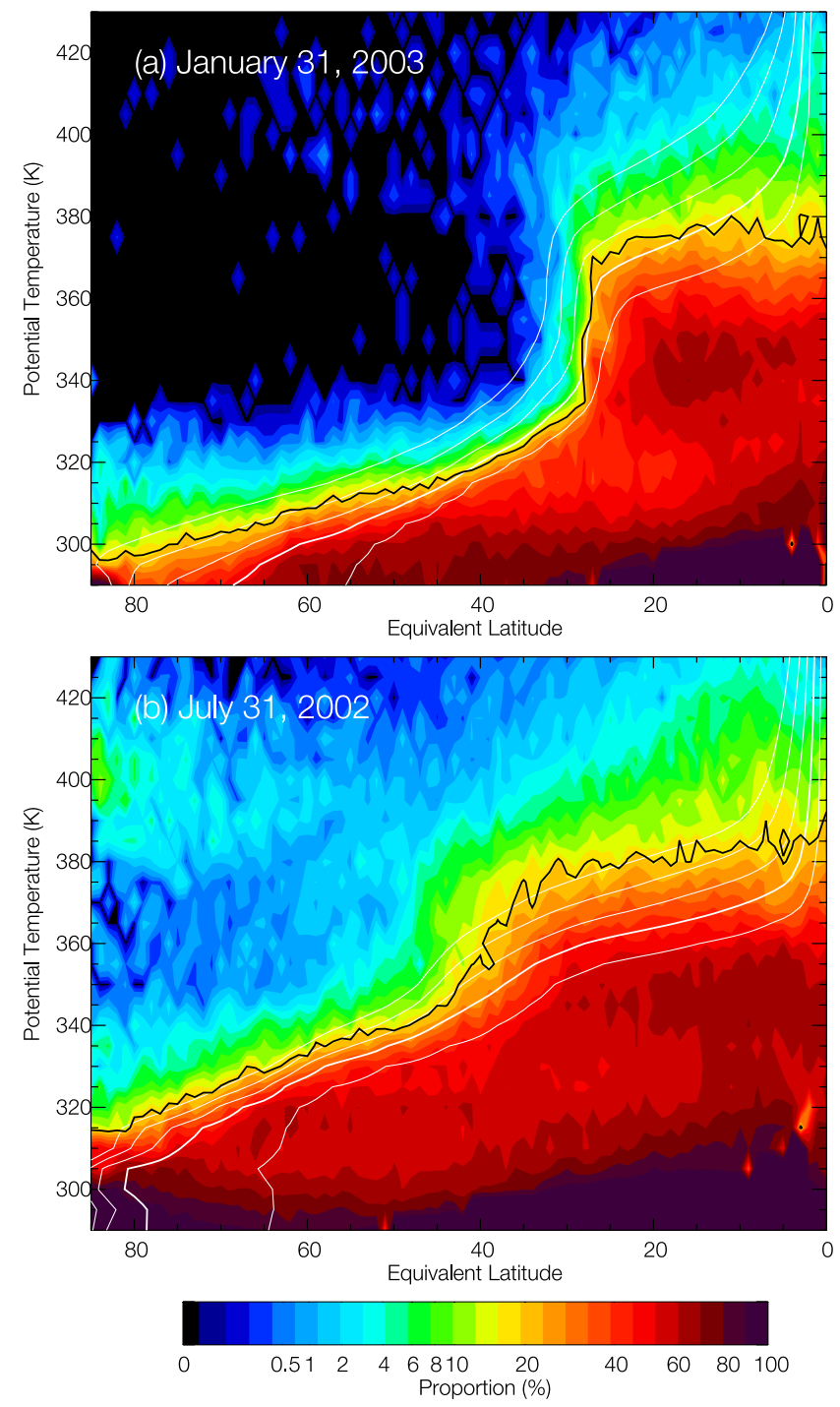

Figure 2. Color contour plot of $\chi_{\mathrm{BL}}\left(\phi_{e}, \theta\right)$, the proportion of trajectories arriving at a given equivalent latitude $\phi_{e}$ and potential temperature $\theta$ location that have encountered the boundary layer $\left(z_{*}<1 \mathrm{~km}\right)$ within the previous 30 days. For comparison, potential vorticity is also contoured (white curves) at values $1,2,4,8$ and 12 PVU with the 2 PVU contour in bold, and the $\chi_{\mathrm{BL}}=20 \%$ contour is plotted in black.

overestimate of "real" stratosphere-troposphere exchange in the extratropics. Arguably, Figure 2 suggests that this region is likely to be best classified as being dynamically and chemically tropospheric. Similarly, a constant PV surface may be a misleading definition of the tropopause in the subtropics in the summer.

[31] Several interesting differences between the winter and summer plots are evident in Figure 2. It is clear that the winter LMS, where typical values of $\chi_{\mathrm{BL}}$ are $1 \%$ or less, is considerably more isolated from the boundary layer, and by implication the troposphere, compared with the summer LMS, where $\chi_{\mathrm{BL}}$ is typically in the range of $1-10 \%$. This result is consistent with several previous studies [e.g., Chen, 1995], based on various modeling results and measurements that have concluded that transport across the extratropical tropopause is more vigorous in the summer than in the winter. Figure 2 provides a useful quantitative comparison of the seasonal differences in the ventilation rates of the LMS. In the winter, in a deep layer from $320-400 \mathrm{~K}$, the LMS extends to equivalent latitudes $30-35^{\circ} \mathrm{N}$, i.e., roughly the location of the winter subtropical jet. In the summer, by contrast, the Lagrangian tropopause slopes equatorward more gradually with increasing potential temperature, with the most pronounced horizontal gradients in $\chi_{\mathrm{BL}}$ present at $40^{\circ} \mathrm{N}$, again corresponding to the position of the jet, which is farther poleward in the summer. Within the summer LMS, there are relatively large variations in $\chi_{\mathrm{BL}}$ with potential temperature, with a relatively isolated layer apparent poleward of $55^{\circ} \mathrm{N}$ between 340 and $370 \mathrm{~K}$ with $\chi_{\mathrm{BL}}<2 \%$, and with a "ventilated layer" directly above between 370 and $410 \mathrm{~K}$, which has $\chi_{\mathrm{BL}} \sim 2-10 \%$ (note that the apparent secondary maximum in $\chi_{\mathrm{BL}}$ on $380 \mathrm{~K}$ at polar latitudes is an artifice of the equivalent latitude method and is not present in other calculated snapshots of $\chi_{\mathrm{BL}}$ ). As will be discussed below, the presence of this ventilated layer is a robust feature of the northern summer LMS and may have important consequences regarding the impact of VSLS on LMS ozone.

[32] The same trajectory calculations may be used to further investigate the nature of the tropopause mixing barrier; for example, to what extent can it be understood as a barrier to quasi-horizontal trajectory motion? Further, what is the strength of this barrier? Figure 3 shows results from the same sets of trajectories as Figure 2 except that they are for $\chi_{10}$. The proportion of particles, which have been south of $10^{\circ} \mathrm{N}$ during the past 30 days is plotted as a function of particle final equivalent latitude and potential temperature. The details of Figure 3 allow the strength of the latitudinal transport barrier associated with the tropopause to be assessed independently of the consideration of vertical transport effects, which are necessarily important in Figure 2. The latitudinal transport barrier is apparent in Figure 3 in both the summer and winter as a large latitudinal gradient in $\chi_{10}$. Poleward of the transport barrier, relatively little air has been as far equatorward as $10^{\circ} \mathrm{N}$ within the previous 30 days (low $\chi_{10}$ ), whereas equatorward of the barrier, $\chi_{10}$ is high as the majority of air parcels have recently crossed the $10^{\circ} \mathrm{N}$ latitude circle. In winter the latitudinal transport barrier is located at $30-35^{\circ} \mathrm{N}$ in the potential temperature range of $320-380 \mathrm{~K}$, consistent with the position of the tropopause identified in Figure 2. It is clear that in the extratropics, $\chi_{10}$ is lowest in the potential temperature range of $330-350 \mathrm{~K}$ and increases with altitude above. The increase of $\chi_{10}$ with height above $380 \mathrm{~K}$ is consistent with the idea of the "tropically controlled transition region" in the range of 380-450 K first proposed by Rosenlof et al. [1997]. Below $330 \mathrm{~K}$ the barrier also weakens and moves poleward with decreasing potential temperature, and at $305 \mathrm{~K}$ it is located at $40-45^{\circ} \mathrm{N}$. Below $305 \mathrm{~K}, \chi_{10}$ has much lower values at all latitudes because isentropes with $290 \mathrm{~K}<\theta<305 \mathrm{~K}$ intersect the ground poleward of $10^{\circ}$, hence relatively few trajectories arriving on these levels are likely to have recently visited equatorial latitudes.

[33] In the summer (Figure 3b), more vertical structure is apparent. The latitudinal barrier is strongest in the range of 

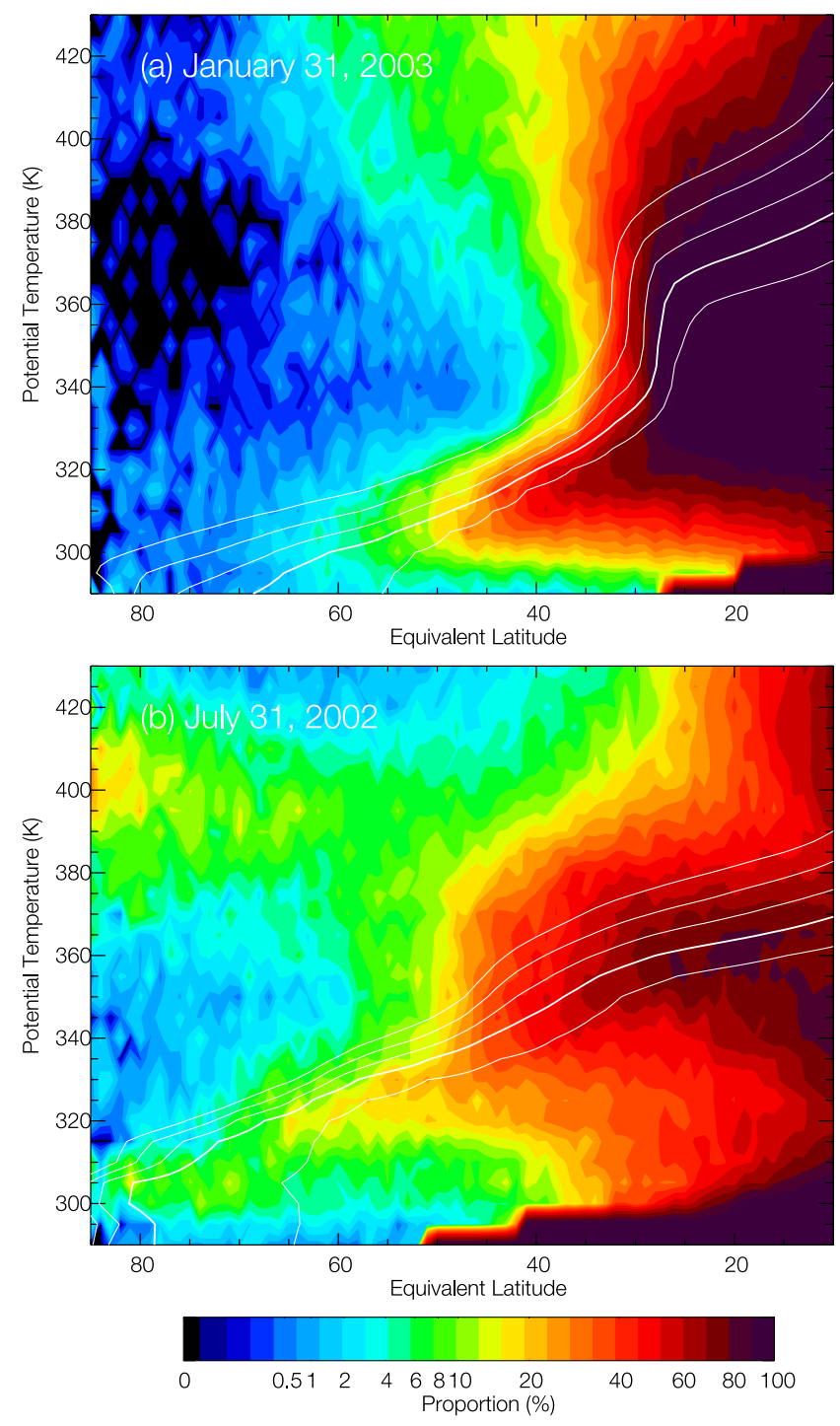

Figure 3. Same as Figure 2 but showing $\chi_{10}\left(\phi_{e}, \theta\right)$, the proportion of trajectories arriving at a given equivalent latitude $\phi_{e}$ and potential temperature $\theta$ location that have crossed the $10^{\circ} \mathrm{N}$ latitude circle within the previous 30 days. Potential vorticity contours at values $1,2,4,8$ and 12 PVU are shown in white with the 2 PVU contour in bold.

$330-380 \mathrm{~K}$, where it is located around $40-45^{\circ} \mathrm{N}$. Above this level, between 380 and $410 \mathrm{~K}$, the barrier is significantly weaker, with substantially higher values of $\chi_{10}$ apparent in the extratropics. The relative weakness of the latitudinal transport barrier between $380-410 \mathrm{~K}$ is clearly consistent with the presence of the "ventilated layer" apparent at these levels in Figure 2b. It is interesting that at higher levels $(410-430 \mathrm{~K})$ the barrier to transport appears to strengthen again but at this time at lower latitudes $\left(\sim 25^{\circ} \mathrm{N}\right)$. Below $330 \mathrm{~K}$ the barrier is noticeably weaker. Another feature of Figure 3 is that where the mixing barrier is strongest, $\chi_{10}$ is relatively high in low latitudes, right up to the mixing barrier itself. This is consistent with the idea that where the mixing barrier is strong, there is relatively strong wave-driven quasi-horizontal stirring of the air equatorward of the barrier. A strong barrier can therefore coexist with strong stirring to its flanks, as has been observed in other contexts [e.g., Juckes and McIntyre, 1987].

[34] The identification in Figures 2 and 3 of a clear maximum in the strength of the quasi-isentropic barrier to transport at certain levels clearly supports the distinction made in section 1 between TST occurring in the extratropics, which primarily affects the ExTL (i.e., the lowest part of the LMS), and TST occurring above the subtropical jet, which has the potential to inject tropospheric air, including boundary layer air, into the LMS at much higher levels. The extratropical TST is largely associated with deep frontal circulations in extratropical cyclones, for example, warm conveyor belts [Stohl et al., 2003]. At the subtropical jet, by contrast, exchange between the tropical tropopause layer (TTL) and the LMS is achieved through quasihorizontal transport. This exchange has been apparent for some time on the basis of observations of subtropical filaments in midlatitudes [Vaughan and Timmis, 1998; O'Connor et al., 1999], water vapor observations [Dessler et al., 1995], and, more recently, chemical observations in the extratropics [Hegglin et al., 2005]. Trajectory and similar transport calculations also show the possibility of such transport, particularly above the level of the subtropical jet [Chen, 1995; Haynes and Shuckburgh, 2000]. Most recently, the trajectory calculations of Levine et al. [2007] show that for the $\mathrm{NH}$ winter much $(\gtrsim 75 \%)$ of the air that enters the tropical tropopause layer [e.g., Gettelman and Forster, 2002] and subsequently reaches the stratosphere does so through quasi-horizontal transport into the extratropical stratosphere.

[35] A picture of seasonal and interannual evolution of $\chi_{\mathrm{BL}}$ and $\chi_{10}$ can be revealed from sets of trajectories initialized twice per month over a 3 year period utilizing the low-resolution grid described in section 2.1. Figure 4 shows the variation of $\chi_{\mathrm{BL}}$ with equivalent latitude and time for trajectories initialized on the $305,335,365$, and $395 \mathrm{~K}$ isentropic surfaces. As in Figures 2 and 3, PV contours are also marked in white. The strong seasonal cycle in the tropopause position is clear on each level. On the $305 \mathrm{~K}$ level, during the northern winter, there is a region in the high latitudes that is sufficiently isolated from the boundary layer to be considered part of the LMS, with the associated winter tropopause remaining poleward of $55^{\circ} \mathrm{N}$. In the summer this region vanishes entirely. At $335 \mathrm{~K}$ the tropopause is seen to be much farther equatorward, being located between around $27^{\circ} \mathrm{N}$ (northern winter) and $55^{\circ} \mathrm{N}$ (northern summer), with rather larger migrations evident for the $\chi_{\mathrm{BL}}=$ $20 \%$ contour (black) compared with the PV $=2$ PVU contour. There is some evidence that the transport characteristics, as diagnosed by the $\chi_{\mathrm{BL}}$ field, change more rapidly from summer to winter regimes than is suggested by the potential vorticity contours. On the $365 \mathrm{~K}$ surface the winter tropopause location is relatively unchanged, but the summer location is significantly equatorward of its $335 \mathrm{~K}$ location. Hence the seasonal cycle is less important at $365 \mathrm{~K}$, and the LMS at this level remains relatively isolated from the boundary layer year round. The seasonal cycle appears to strengthen again at the $395 \mathrm{~K}$ level, consistent with the weaker barrier to isentropic transport at this level apparent in Figure 3, and in the summer, $\chi_{\mathrm{BL}}$ reaches $0.5-4 \%$, i.e., 

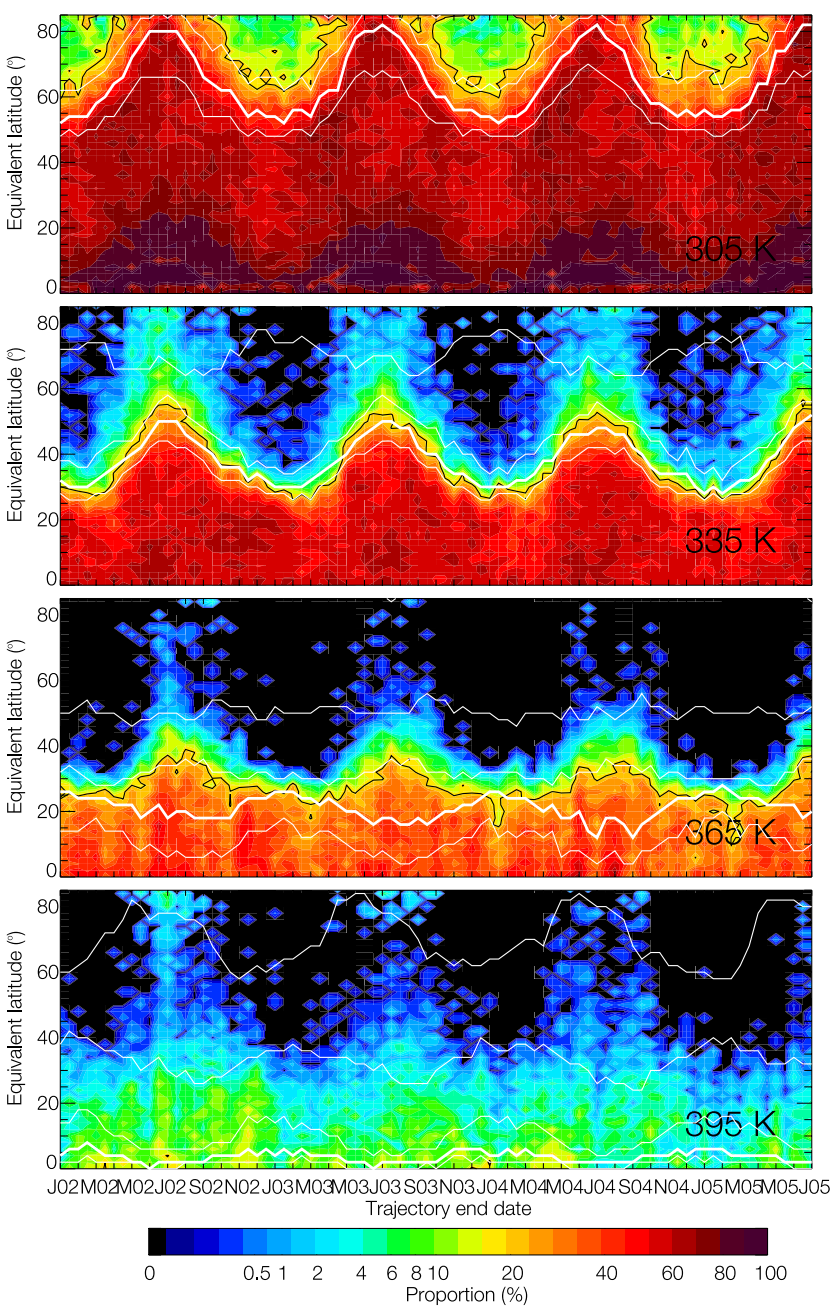

Figure 4. Contour plots of $\chi_{\mathrm{BL}}$, the proportion of particles to have seen the boundary layer within the previous 30 days on fixed isentropic levels $\theta=305,335,365$, and $395 \mathrm{~K}$ as a function of $\phi_{e}$ and time, illustrating the evolving seasonal cycle over the period December 2001 to July 2005. Potential vorticity contours at values $1,2,4,8$, and 12 PVU are shown in white with the 2 PVU contour in bold. The $\chi_{\mathrm{BL}}=20 \%$ contour is plotted in black.

higher than on the $365 \mathrm{~K}$ surface and arguably an indicator of chemically significant transport.

[36] For comparison, Figure 5 shows the seasonal variation of $\chi_{10}$ with equivalent latitude and time. Comparing the results with Figure 4, the tropopause is seen to be aligned with a large jump in $\chi_{10}$ at each level, illustrating the corresponding seasonal evolution of the latitudinal barrier to transport. Figure 5 shows that the latitudinal barrier is almost impermeable in both the summer and winter at $335 \mathrm{~K}$ and $365 \mathrm{~K}$ and also on $395 \mathrm{~K}$ in the winter but is relatively leaky on $395 \mathrm{~K}$ in the summer. A strong transport barrier is invariably associated with high values of $\chi_{10}$ on its equatorward side, indicating that efficient stirring of tropospheric air is taking place. On the $305 \mathrm{~K}$ surface the picture is complicated by the fact that much of the $305 \mathrm{~K}$ isentrope typically intersects the ground poleward of $10^{\circ} \mathrm{N}$.

\subsection{Source Regions for Transport of Boundary Layer} Air to the Lowermost Stratosphere

[37] Understanding the details of the transport of air from the boundary layer to the lowermost stratosphere is of particular importance because of the possibility of the transport of chemically active trace gases directly to the LMS from their emission sites. One particular possibility is that of halogenated VSLS being mixed with ozone-rich LMS air [Bridgeman et al., 2000; Ko et al., 2003]. Quantifying the effect of the VSLS on the LMS ozone budget is difficult not only because of uncertainties surrounding chemical sources and reaction pathways [Ko et al., 2003] but also because transport pathways and mixing history may not be well represented in global chemistry transport models using finite resolutions. Beyond knowledge of the TST mass flux, at least three further factors must be important in quantifying the effect of trace gases such as VSLS on the LMS ozone budget.

[38] 1. From which geographical region does the boundary layer air reaching the LMS originate? In particular, do regions where strong uplift of boundary layer air occurs
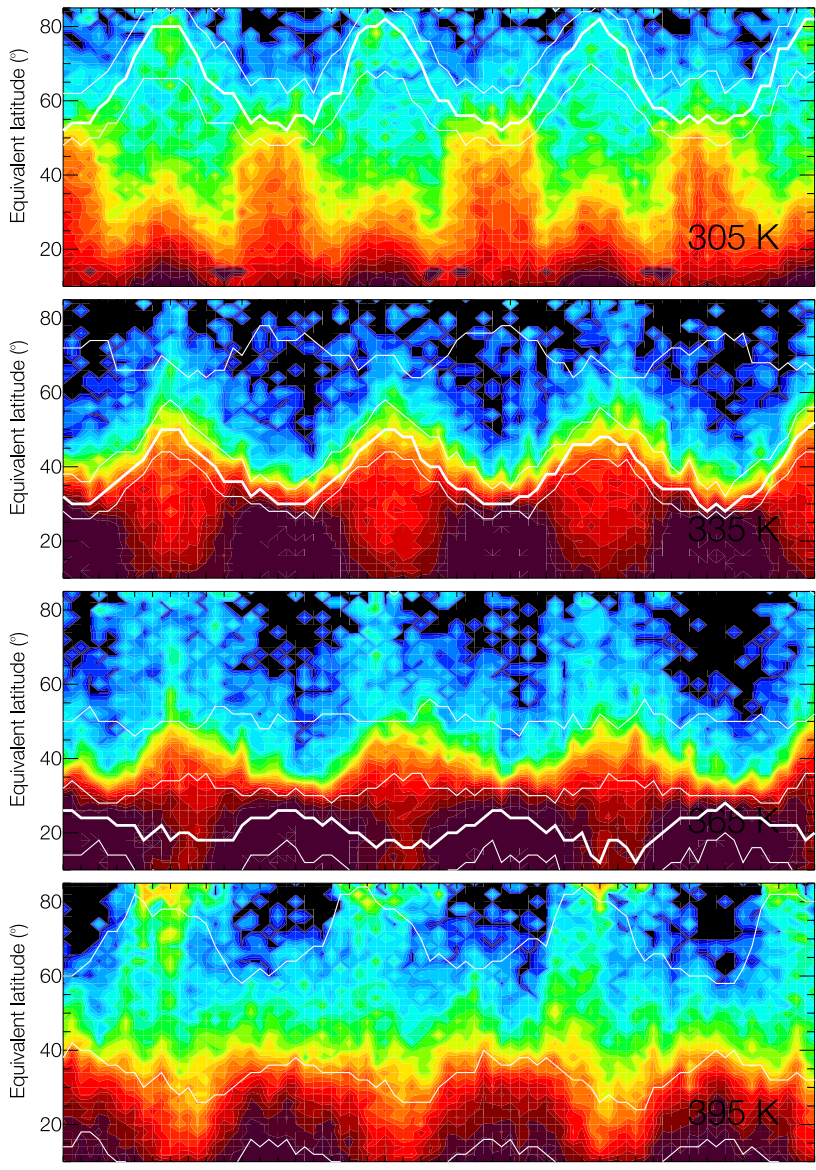

J02M02M02J02S02N02J03M03M03J03S03N03J04M04M04J04 SO4N04J05M05M05J05

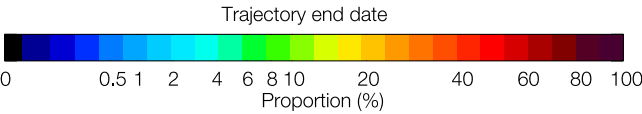

Figure 5. Same as Figure 4 but for $\chi_{10}$, the proportion of particles to have crossed the $10^{\circ} \mathrm{N}$ latitude circle within the previous 30 days. 

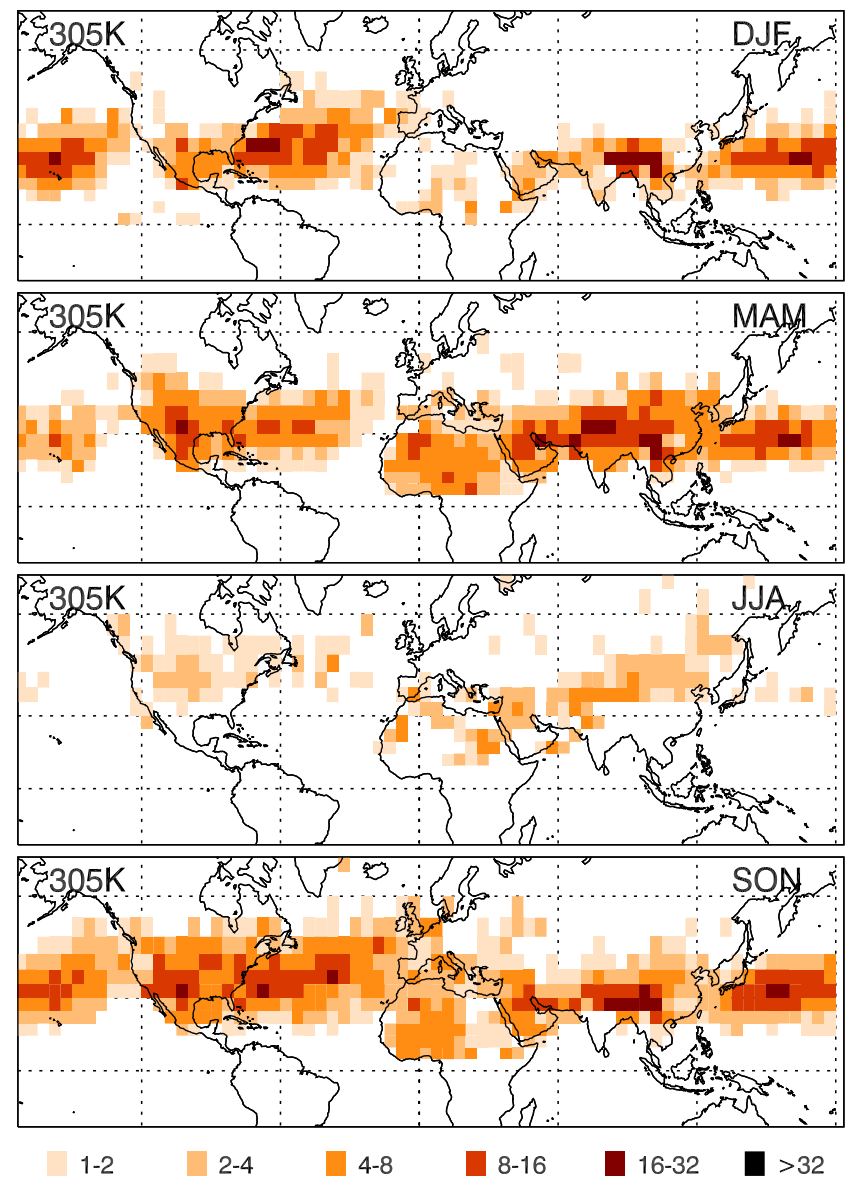

Figure 6. Density field $\rho_{305 \mathrm{~K}}(\lambda, \phi)$ calculated for those trajectories leaving the boundary layer $\left(z_{*}<1 \mathrm{~km}\right)$ that subsequently arrive in the stratosphere on the $305 \mathrm{~K}$ isentropic surface (i.e., attaining PV $>2$ PVU) for the Northern Hemisphere winter (DJF), spring (MAM), summer (JJA), and fall (SON) seasons. The density field is calculated by averaging over all trajectories leaving the boundary layer and reaching the stratosphere on $305 \mathrm{~K}$ during each 3 month season within the period December 2001 to August 2005. The density field is then normalized by its expected value in the case where trajectories are equally likely to leave the boundary layer at any location on the Earth's surface and at a uniform rate in time.

coincide with industrial regions where important VSLS sources are present?

[39] 2. To what extent does the boundary layer air mix with background tropospheric air during the course of uplift to the LMS?

[40] 3. To which levels in the LMS is the boundary layer air transported? The chemical effect of the VSLS on LMS ozone is necessarily related to the ozone concentrations encountered, and chemical measurements [e.g., Hoor et al., 2002] reveal a very strong vertical gradient in ozone within the LMS. Although the interplay between the various catalytic cycles that deplete ozone is complex, the modeling study of Salawitch et al. [2005] shows that the ozone depletion potential of bromine-based VSLS increases up to $16 \mathrm{~km}$, which corresponds approximately to the top of the LMS (as defined by $380 \mathrm{~K}$ ) in the extratropics. Within the
LMS therefore the higher the altitude to which emitted VSLS are transported, the stronger the ozone depleting effect will be.

[41] Three-dimensional trajectory data sets can be used to investigate factors 1 and 3. Little can be inferred from the trajectory data about factor 2 , however, but the success of back trajectory techniques in identifying polluted airmasses up to 10 or more days downstream of their corresponding chemical sources [e.g., Methven et al., 2001] shows that tropospheric air frequently retains a strong chemical influence from the region of the boundary layer where uplift previously occurred. One important process to determine factor 2 for extratropical TST is the extent of entrainment and mixing in warm conveyor belt frontal circulations [Purvis et al., 2003; Esler et al., 2003; Mari et al., 2004]. These studies indicate that there is substantial convective injection of local boundary layer air into the warm conveyor belt but that this may occur in a localized region within the broad ascending conveyor belt airmass. For tropical TST the mixing behavior will instead likely be controlled by deep cumulonimbus convection and its mesoscale and synopticscale organization. In both cases these are largely subgrid processes for global CTMs.

[42] A measure of the relative importance of different boundary layer regions as sources for transport to the LMS is the density field $\rho_{\theta}(\lambda, \phi)$ defined in section 2.1. The $\rho_{\theta}$ $(\lambda, \phi)$ fields to be shown are calculated from sets of 30 day back trajectories arriving in the stratosphere during the period December 2001 to August 2005. In Figure 6, $\rho_{305 \mathrm{~K}}$ is shown for the northern winter (DJF), spring (MAM), summer (JJA), and fall (SON) seasons, illustrating the relative importance of different geographical regions as sources for trajectories leaving the boundary layer and subsequently arriving in the stratosphere (at $t=0$ ) on the $305 \mathrm{~K}$ isentropic surface. The average of several years of trajectory data has been taken to "smooth" the picture and to ensure that the influence of any anomalous climatic period is minimized. However, the same picture plotted for individual years gives almost identical results, emphasizing the robustness of the methodology and indicating an apparently low level of interannual variability. One first impression, taking note of the geometric progression of the color scale in Figure 6, is that the regions of significant boundary layer sources are strongly localized geographically. Nearly all $(94.2 \%)$ trajectories leaving the boundary layer and reaching the stratosphere are found to depart from the shaded regions (where $\rho_{\theta}>1$ ) and nearly half (44.2\%) depart from the "red" regions (where $\rho_{\theta}>8$ ). The red regions cover at most $4 \%$ of the Earth's surface in each of the seasons as shown in Figure 6.

[43] In the northern winter (DJF), three principal source regions for transport from the boundary layer to the $305 \mathrm{~K}$ isentropic surface in the stratosphere are apparent. These can be associated with the Atlantic storm track, the Pacific storm track, and the Himalayan plateau. The same three regions are also of primary importance during the spring (MAM) and fall (SON) seasons, although during the spring and fall other source regions, such as the western United States, northwest Africa, and the Arabian peninsula, are also significant. In the summer (JJA), there is very little transport to the stratosphere on the $305 \mathrm{~K}$ surface: This is because in the summer the stratosphere, as defined by the PV $=2 \mathrm{PVU}$ 

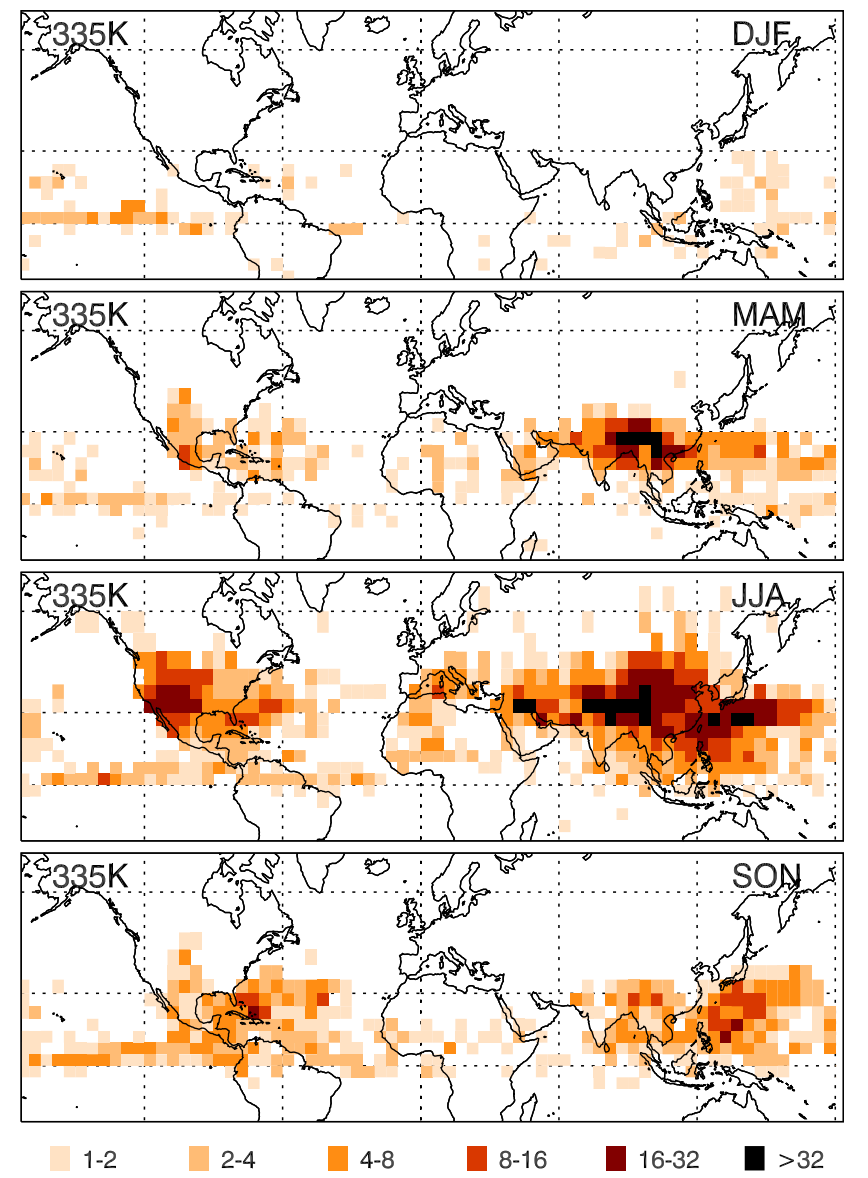

Figure 7. Same as Figure 6 but showing $\rho_{335 \mathrm{~K}}(\lambda, \phi)$, the density of trajectories leaving the boundary layer $(z *<1 \mathrm{~km})$ that subsequently arrive in the stratosphere on the $335 \mathrm{~K}$ isentropic surface.

surface, vanishes from the $305 \mathrm{~K}$ surface altogether, as can be seen in Figure 4.

[44] Examination of individual trajectories in the Atlantic and Pacific storm track regions shows that large numbers experience rapid uplift in frontal circulations from the boundary layer to the locality of the tropopause. The Pacific and Atlantic storm track source regions on the $305 \mathrm{~K}$ surface correspond closely to the warm conveyor belt "starting locations" identified by Stohl [2001, Figure 1]. The important difference between our approach and that of Stohl [2001] is that our source regions are based on trajectories that subsequently arrive in the stratosphere on a given isentropic level, rather than those that experience significant frontal uplift (of $8000 \mathrm{~m}$ ). The fact that the same storm track source regions are identified in both approaches indicates that frontal uplift is a strong precondition for a trajectory to reach the LMS at $305 \mathrm{~K}$. After undergoing such uplift, whether or not a specific trajectory will then subsequently enter the LMS appears to be a largely random process. Hence, compared with the boundary layer source regions in Figure 6, the distribution of trajectory entry points into the LMS, as shown, for example, in Figure 1 of Sprenger and Wernli [2003], is relatively smooth in longitude, with around a factor of 2 in magnitude between minima and maxima. Sprenger and Wernli [2003, Figure 5b] also show a plot of trajectory "origin" location for trajectories subsequently undergoing deep TST during the northern winter. The trajectory origins found by Sprenger and Wernli [2003] can also be identified with the Pacific and Atlantic storm tracks and are located slightly downstream of the corresponding regions shown in Figure 6. This difference is consistent with the fact that the density field calculated by Sprenger and Wernli [2003] is derived from trajectory locations calculated a fixed time before TST takes place, rather than from the locations where the trajectories left the boundary layer.

[45] Although there are many similarities between our Figure 6 and Stohl's [2001] Figure 1, there are also some significant differences. For most of the year the Himalayan plateau, and to a lesser extent the western United States, also acts as significant sources for the transport from the boundary layer to the stratosphere but are not found to be significant starting points for warm conveyor belts. Examination of trajectory behavior in these regions reveals that because trajectories leaving the boundary have relatively high starting altitudes, and hence high potential temperatures, they need to experience relatively little diabatic heating (e.g., due to latent heat release) in order to reach isentropic surfaces that intersect the tropopause. The overall change in altitude above the ground during this process is typically less than the $8000 \mathrm{~m}$ necessary for the trajectory to be associated with a warm conveyor belt, but the trajectory is nevertheless transported from the boundary layer to the LMS.

[46] Figure 7 shows $\rho_{335 \mathrm{~K}}$, the density field illustrating the source regions for trajectories transported from the boundary layer to the LMS on the $335 \mathrm{~K}$ isentropic surface. Consistent with the relative strengths of the transport barrier identified in Figure 2, most transport to the $335 \mathrm{~K}$ surface occurs in the Northern Hemisphere summer season (JJA), with very little direct transport in the winter (DJF). In the summer (JJA), three main source regions are apparent: the western central United States; the Himalayan plateau, including much of central China; and finally, the western Pacific storm track, including southern Japan and the east coast of China. The Atlantic storm track is a secondary source. The western United States and Himalayan plateau act as sources because trajectories have relatively high starting potential temperatures and elevations, as discussed above. If convective processes were captured by the ECMWF winds, it is possible that these elevated regions would appear as stronger source regions for transport to the LMS at this level because recent studies [Dessler and Sherwood, 2004; Fu et al., 2006] have shown that deep convective penetration of the stratosphere may be important over the North American continent and Himalayan plateau in the summer. A further interesting feature of Figure 7 is the seasonal trend in the importance of different sources: In the fall (SON) the Pacific and Atlantic storm track source regions are much more significant than in the spring (MAM), when the Himalayan and western United States sources dominate.

[47] Figure 8 shows the density field of source regions for trajectory transport from the boundary layer to the LMS on the $365 \mathrm{~K}$ surface $\rho_{365 \mathrm{~K}}$. Because the most significant sources are in the deep tropics for this isentropic level, the details of the ECMWF trajectories, which are discussed 

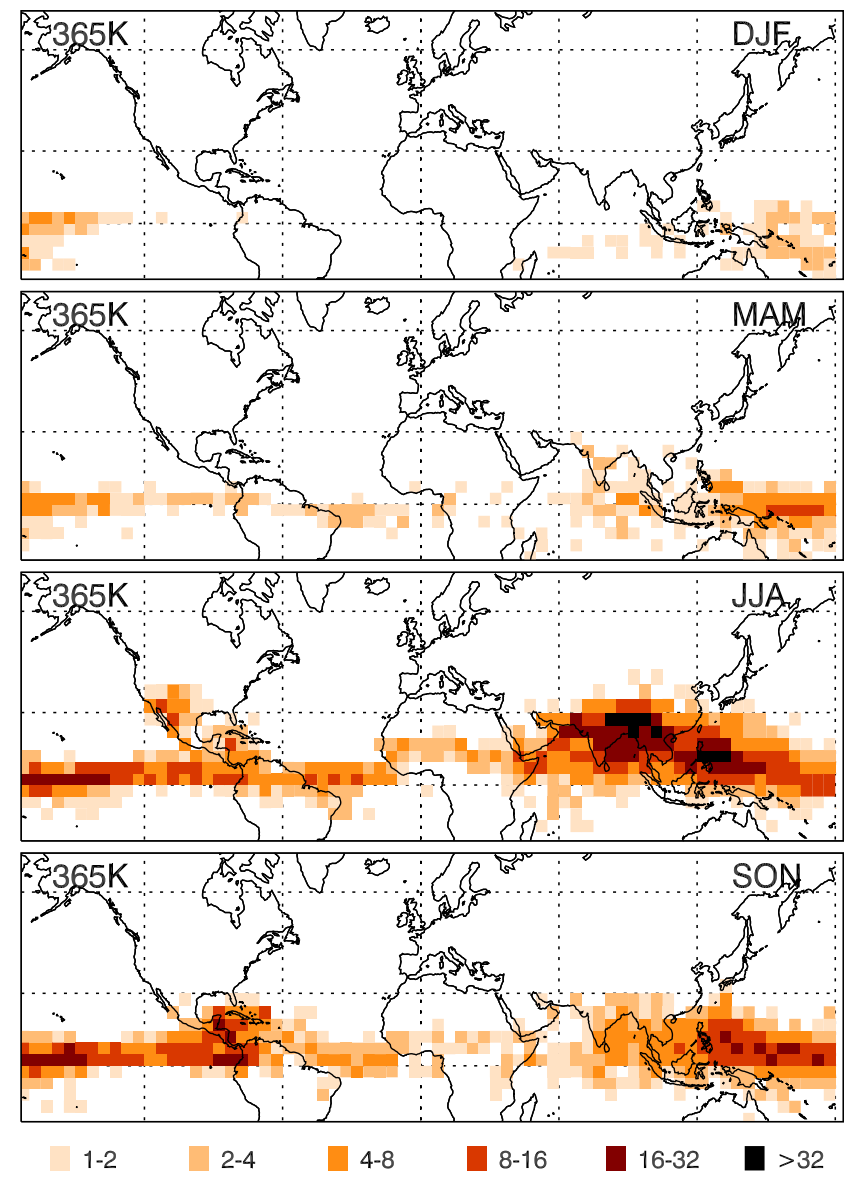

Figure 8. Same as Figure 6 but showing $\rho_{365 \mathrm{~K}}(\lambda, \phi)$, the density of trajectories leaving the boundary layer $(z *<1 \mathrm{~km})$ that subsequently arrive in the stratosphere on the $365 \mathrm{~K}$ isentropic surface.

above, must differ significantly from those calculated from wind fields, which resolve all spatial scales in the tropical troposphere and must therefore be of central importance in determining these results. However, there are reasons to believe that the pathways, although not the timescales associated with those pathways, shown in Figure 8 are at least approximately correct. Regions of strong deep convection, such as the western tropical Pacific, are characterized by correspondingly strong large-scale ascent in the ECMWF winds. The pathways for injection of boundary layer air into the TTL therefore appear in trajectory calculations to be at least qualitatively correct, albeit not for the right reasons. Subsequently, although the relative roles of convection and large-scale ascent in determining upward and poleward transport from the TTL have not been entirely clarified, it is notable that calculations based on large-scale trajectories [Fueglistaler et al., 2005; Bonazzola and Haynes, 2004] can account for many details of the seasonal and interannual distribution of water vapor concentrations in the tropical lower stratosphere. Levine et al. [2007] have also investigated transport from the TTL to the extratropical LMS. They compared results from sets of forward trajectories, initialized in the TTL during January 2001, with a similarly initialized tracer field advected in a chemistry transport model. Near identical results were obtained, provided the chemistry transport model is run at sufficiently high resolution, regardless of whether the model's convective parameterization is switched on or not.

[48] The main sources in Figure 8 can be strongly associated with regions of deep convection: the western tropical Pacific and maritime continent, the Himalayan plateau and Indian subcontinent, and a thin equatorial source corresponding to the ITCZ. All sources are stronger in the northern summer (JJA) compared with the winter (DJF), but it is clear that the strongest seasonality is for the Himalayan/Indian subcontinent source, which is mainly present in the summer (JJA) and can thus be largely associated with the Indian monsoon. The $365 \mathrm{~K}$ source regions correlate well with indirect measurements of convective strength, including chemical concentrations of species emitted in the boundary layer [Li et al., 2005] and cloudiness [Jiang et al., 2004]. Returning to the idea of separate extratropical and tropical pathways for TST, the changes in the source regions with increasing altitude (from Figure 6 to Figure 8) can be associated with weaker contributions from the primarily extratropical TST source regions (e.g., the Pacific and Atlantic storm tracks, western United States, and Himalayas) and stronger contributions from tropical TST source regions (e.g., the Indian subcontinent and tropical western Pacific).

[49] In summary, Figures 6, 7, and 8 concisely illustrate the source-destination relationship for the direct transport of air parcels from the boundary layer to the LMS, subject to the caveats regarding the trajectory calculations outlined in section 2.2. In terms of the impact of the VSLS on stratospheric ozone, Figures 6, 7, and 8 show that the transport pathways likely to be most important are those sources located over land from which air parcels can be directly transported to the $365 \mathrm{~K}$ surface, which can be seen to have significant magnitude mainly in the northern summer (JJA). These source regions are boundary layer regions from which emissions of VSLS can be directly transported to the upper LMS, where ozone concentrations are relatively high and the ozone depletion potential of the transported VSLS is likely to be greatest. Very similar source regions to those shown in Figure 8 were also found for transport from the boundary layer to the $395 \mathrm{~K}$ surface, indicating that this transport occurs into a layer of the stratosphere with significant thickness. Conclusions drawn from Figures 6, 7 , and 8 must be considered tentative, however, pending a better quantitative understanding of the mixing processes undergone by air parcels during this journey. Figures 6,7 , and 8 can be misleading if not considered in the context of the method and metric applied. It should be kept in mind that the results were obtained in the context of the $\mathrm{NH}$ latitudes only and different source areas might be emphasized for calculations encompassing both hemispheres.

\section{Conclusions}

[50] In this study, trajectories driven by ECMWF operational analysis wind fields have been used to make a novel characterization of the transport properties of the tropopause region and lowermost stratosphere and also to indicate those regions in the atmospheric boundary layer that act as the sources of the air that ventilates the LMS region. The result 
is a quantitative picture of the relative rates of, as well as the ultimate sources for, troposphere to stratosphere transport into different regions of the LMS in the Northern Hemisphere winter and summer.

[51] A clear picture of the location and seasonal evolution of the barrier to transport associated with the tropopause emerges from our study, as seen in Figures 2, 3, 4, and 5. We have defined a Lagrangian tropopause in terms of the proportion of trajectories that have visited the boundary layer within a fixed time period. An important point is that in the extratropics the difference between the position of the Lagrangian tropopause and the $\mathrm{PV}=2$ PVU surface may put a significant degree of uncertainty to studies using constant PV surfaces as a reference, thus possibly biasing previous estimations of stratosphere-troposphere exchange. The methodology described serves to verify and quantify previous conclusions about the relative permeability of the barrier in the winter and summer [e.g., Chen, 1995], showing that the rate of ventilation of the northern extratropical LMS can be up to an order of magnitude greater in the summer compared with the winter. Interannual variability does not appear to be very significant, at least for the period of the study (2002-2005). New conclusions can also be drawn about the variation of the strength of the barrier to transport with altitude, expanding on those of, e.g., Haynes and Shuckburgh [2000]. For example, in the northern summer it is clear that a layer in the LMS spanning 370$410 \mathrm{~K}$ is relatively well ventilated with tropospheric air compared with lower levels in the LMS (340-370 K) and that this "ventilated layer" is due to the barrier to transport being weaker at these levels. A distinction is therefore justified between tropical TST, which can involve transport directly from the tropical boundary layer to this ventilated layer, and extratropical TST, which occurs primarily into the ExTL located below $340 \mathrm{~K}$. A similar distinction can also be made in the northern winter, although the barrier to transport remains relatively impermeable at upper levels and tropical TST is relatively weak. This seasonality in the ventilation of the LMS predicted by the trajectories is consistent with previous deductions from in situ and satellite measurements of chemical species [Ray et al., 1999; Pan et al., 2000; Hoor et al., 2005].

[52] The possibility that air masses from different regions of the atmospheric boundary layer have dramatically different likelihoods of being involved in TST within a timescale of a few weeks has clear policy implications for the control of VSLS and other trace gases. Figures 6, 7, and 8 certainly raise this possibility, as the current methodology, focusing on the location where trajectories leave the boundary layer, demonstrates the existence of large boundary layer regions for which negligible direct trajectory transport to the LMS occurs. This result is in agreement with previous studies of TST source regions employing alternative methodologies [Sprenger and Wernli, 2003]. It is tempting to conclude that emissions of VSLS in these boundary layer regions with no direct transport pathway to the LMS will have relatively little impact on lower stratospheric ozone compared with emissions in the red highlighted "source" regions. However, the trajectory study presented here represents only one extreme situation: a "no mixing" view of atmospheric transport, in contrast to CTM experiments, which must necessarily involve "too much mixing" even at high resolution. The general effect of mixing and subgrid convective processes on the source regions shown in Figures 6, 7 , and 8 , whether in the atmosphere, a CTM experiment, or via a stochastic parameterization of subgrid effects applied to the trajectory calculations [James et al., 2003a], is likely to be to diffuse the sources over wider regions. Further work is necessary to quantify the extent of this effect, and for now the results shown in Figures 6,7 , and 8 might be best viewed in conjunction with those from CTM experiments, such as those of Levine et al. [2007]. Nevertheless, Figures 6, 7 , and 8 might be regarded as an attempt to develop a climatology of boundary layer source regions for boundary layer to stratosphere transport following the lead of Wernli and Bourqui [2002]. Such a climatology is necessary to assess the chemical impact of a range of trace gases, particularly those with relatively short lifetimes such as VSLS, for which relatively crude measures such as crosstropopause mass fluxes are likely to be misleading.

[53] Acknowledgments. G. W. B. and P. H. H. would like to acknowledge support from the Isaac Newton Trust and from the EU SCOUT-O3 integrated project.

\section{References}

Bonazzola, M., and P. H. Haynes (2004), A trajectory-based study of the tropical tropopause region, J. Geophys. Res., 109, D20112, doi:10.1029/ 2003JD004356

Bourqui, M. S. (2006), Stratosphere-troposphere exchange from the Lagrangian perspective: A case study and method sensitivities, Atmos. Chem. Phys., 6, 2651-2670.

Bridgeman, C. H., J. A. Pyle, and D. E. Shallcross (2000), A threedimensional model calculation of the ozone depletion potential of 1-bromopropane (1- $\left.\mathrm{C}_{3} \mathrm{H}_{7} \mathrm{Br}\right)$, J. Geophys. Res., 105, 26,493-26,502.

Butchart, N., and E. E. Remsberg (1986), The area of the stratospheric polar vortex as a diagnostic for tracer transport on an isentropic surface, J. Atmos. Sci., 43, 1319-1339.

Chen, P. (1995), Isentropic cross-tropopause mass exchange in the extratropics, J. Geophys. Res., 100, 16,661-16,674.

Dessler, A. E., and S. C. Sherwood (2004), Effect of convection on the summertime extratropical lower stratosphere, J. Geophys. Res., 109, D23301, doi:10.1029/2004JD005209.

Dessler, A. E., E. J. Hintsa, E. M. Weinstock, J. G. Anderson, and K. R. Chan (1995), Mechanisms controlling water vapor in the lower stratosphere: "A tale of two stratospheres", J. Geophys. Res., 100, 23,16723,172 .

Dethof, A., A. O'Neill, and J. Slingo (2000), Quantification of the isentropic mass transport across the dynamical tropopause, J. Geophys. Res., $105,12,279-12,294$.

Dvortsov, V. L., M. A. Geller, S. Solomon, S. M. Schauffler, E. L. Atlas, and D. R. Blake (1999), Rethinking reactive halogen budgets in the midlatitude lower stratosphere, Geophys. Res. Lett., 26, 1699-1702.

Esler, J. G., P. H. Haynes, K. S. Law, H. Barjat, K. Dewey, J. Kent, S. Schmitgen, and N. Brough (2003), Transport and mixing between airmasses in cold frontal regions during Dynamics and Chemistry of Frontal Zones (DCFZ), J. Geophys. Res., 108(D4), 4142, doi:10.1029/ 2001JD001494.

Fischer, H., F. G. Wienhold, P. Hoor, O. Bujok, C. Schiller, P. Siegmund, M. Ambaum, H. A. Scheeren, and J. Lelieveld (2000), Tracer correlations in the northern high latitude lowermost stratosphere: Influence of crosstropopause mass exchange, Geophys. Res. Lett., 27, 97-100.

Fischer, H., et al. (2003), Deep convective injection of boundary layer air into the lowermost stratosphere at midlatitudes, Atmos. Chem. Phys., 3, $739-745$

Forster, P. M. de F., and K. P. Shine (1997), Radiative forcing and temperature trends from stratospheric ozone changes, J. Geophys. Res., 102, $10,841-10,856$

$\mathrm{Fu}, \mathrm{R}$, et al. (2006), Short circuit of water vapor and polluted air to the global stratosphere by convective transport over the Tibetan Plateau, Proc. Natl. Acad. Sci. U. S. A., 103, 5664-5669.

Fueglistaler, S., H. Wernli, and T. Peter (2004), Tropical troposphere-tostratosphere transport inferred from trajectory calculations, J. Geophys. Res., 109, D03108, doi:10.1029/2003JD004069.

Fueglistaler, S., M. Bonazzola, P. H. Haynes, and T. Peter (2005), Stratospheric water vapor predicted from the Lagrangian temperature history of 
air entering the stratosphere in the tropics, J. Geophys. Res., 110, D08107, doi:10.1029/2004JD005516.

Gettelman, A., and P. M. de F. Forster (2002), Definition and climatology of the tropical tropopause layer, J. Meteorol. Soc. Jpn., 80, 911-924.

Haynes, P. H., and E. F. Shuckburgh (2000), Effective diffusivity as a diagnostic of atmospheric transport: 2. Troposphere and lower stratosphere, J. Geophys. Res., 105, 22,795-22,810.

Hegglin, M. I., et al. (2004), Tracing troposphere to stratosphere transport within a mid-latitude deep convective system, Atmos. Chem. Phys., 4, $741-756$.

Hegglin, M. I., D. Brunner, T. Peter, J. Staehelin, V. Wirth, P. Hoor, and H. Fischer (2005), Determination of eddy diffusivity in the lowermost stratosphere, Geophys. Res. Lett., 32, L13812, doi:10.1029/ 2005GL022495.

Hintsa, E. J., et al. (1998), Troposphere-to-stratosphere transport in the lowermost stratosphere from measurements of $\mathrm{H}_{2} \mathrm{O}, \mathrm{CO}_{2}, \mathrm{~N}_{2} \mathrm{O}$ and $\mathrm{O}_{3}$, Geophys. Res. Lett., 25, 2655-2658.

Holton, J. R., P. H. Haynes, M. E. McIntyre, A. R. Douglass, R. B. Rood, and L. Pfister (1995), Stratosphere-troposphere exchange, Rev. Geophys, 33, $403-439$.

Hoor, P., H. Fischer, L. Lange, J. Lelieveld, and D. Brunner (2002), Seasonal variations of a mixing layer in the lowermost stratosphere as identified by the $\mathrm{CO}-\mathrm{O}_{3}$ correlation from in situ measurements, J. Geophys. Res., 107(D5), 4044, doi:10.1029/2000JD000289.

Hoor, P., C. Gurk, D. Brunner, M. Hegglin, H. Wernli, and H. Fischer (2004), Seasonality and extent of extratropical TST derived from in-situ CO measurements during SPURT, Atmos. Chem. Phys., 4, 1427-1442.

Hoor, P., H. Fischer, and J. Lelieveld (2005), Tropical and extratropical tropospheric air in the lowermost stratosphere over Europe: A CO-based budget, Geophys. Res. Lett., 32, L07802, doi:10.1029/2004GL022018.

James, P., A. Stohl, C. Forster, S. Eckhardt, P. Seibert, and A. Frank (2003a), A 15-year climatology of stratosphere-troposphere exchange with a Lagrangian particle dispersion model: 1. Methodology and validation, J. Geophys. Res., 108(D12), 8519, doi:10.1029/2002JD002637.

James, P., A. Stohl, C. Forster, S. Eckhardt, P. Seibert, and A. Frank (2003b), A 15-year climatology of stratosphere-troposphere exchange with a Lagrangian particle dispersion model: 2 . Mean climate and seasonal variability, J. Geophys. Res., 108(D12), 8522, doi:10.1029/ 2002JD002639.

Jiang, J. H., B. Wang, K. Goya, K. Hocke, S. D. Eckermann, J. Ma, D. L. Wu, and W. G. Read (2004), Geographical distribution and interseasonal variability of tropical deep convection: UARS MLS observations and analyses, J. Geophys. Res., 109, D03111, doi:10.1029/2003JD003756.

Juckes, M. N., and M. E. McIntyre (1987), A high-resolution one-layer model of breaking planetary waves in the stratosphere, Nature, 328, $590-596$.

Ko, M. K. W., et al. (2003), Very short-lived halogen and sulfur substances, in Scientific Assessment of Ozone Depletion: 2002, Tech. Rep. 47, World Meteorol. Organ., Geneva.

Krebsbach, M., C. Schiller, D. Brunner, G. Günther, M. I. Hegglin, D. Mottaghy, M. Riese, N. Spelten, and H. Wernli (2006), Seasonal cycles and variability of $\mathrm{O}_{3}$ and $\mathrm{H}_{2} \mathrm{O}$ in the UT/LMS during SPURT, Atmos. Chem. Phys., 6, 109-125.

Levine, J. G., P. Braesicke, N. R. P. Harris, N. H. Savage, and J. A. Pyle (2007), Pathways and timescales for troposphere-to-stratosphere transport via the tropical tropopause layer and their relevance for very short lived substances, J. Geophys. Res., 112, D04308, doi:10.1029/2005JD006940.

Li, Q., et al. (2005), Convective outflow of South Asian pollution: A global CTM simulation compared with EOS MLS observations, Geophys. Res. Lett., 32, L14826, doi:10.1029/2005GL022762.

Mari, C., M. J. Evans, P. I. Palmer, D. J. Jacob, and G. W. Sachse (2004), Export of Asian pollution during two cold front episodes of the TRACE-P experiment, J. Geophys. Res., 109, D15S17, doi:10.1029/2003JD004307.

Meijer, E. W., B. Bregman, A. Segers, and P. F. J. van Velthoven (2004), The influence of data assimilation on the age of air calculated with a global chemistry-transport model using ECMWF wind fields, Geophys. Res. Lett., 31, L23114, doi:10.1029/2004GL021158.

Methven, J. (1997), Offline trajectories: Calculation and accuracy, Tech. Rep. 44, Dep. of Meteorol., Univ. of Reading, Reading, U. K.

Methven, J., M. Evans, P. Simmonds, and G. Spain (2001), Estimating relationships between air mass origin and chemical composition, J. Geophys. Res., 106, 5005-5020.

O’Connor, F. M., G. Vaughan, and H. De Backer (1999), Observations of subtropical air in the European mid-latitude lower stratosphere, $Q . J . R$. Meteorol. Soc., 125, 2965-2986.

Pan, L. L., E. J. Hintsa, E. M. Stone, E. M. Weinstock, and W. J. Randel (2000), The seasonal cycle of water vapor and saturation vapor mixing ratio in the extratropical lowermost stratosphere, J. Geophys. Res., 105, 26,519-26,530

Pan, L. L., W. J. Randel, B. L. Gary, M. J. Mahoney, and E. J. Hintsa (2004), Definitions and sharpness of the extratropical tropopause: A trace gas perspective, J. Geophys. Res., 109, D23103, doi:10.1029/ 2004JD004982.

Poulida, O., R. R. Dickerson, and A. Heymsfield (1996), Stratospheretroposphere exchange in a midlatitude mesoscale convective complex: 1. Observations, J. Geophys. Res., 101, 6823-6836.

Purvis, R. M., et al. (2003), Rapid uplift of nonmethane hydrocarbons in a cold front over central Europe, J. Geophys. Res., 108(D7), 4224, doi:10.1029/2002JD002521.

Ray, E. A., F. L. Moore, J. W. Elkins, G. S. Dutton, D. W. Fahey, H. Vömel, S. J. Oltmans, and K. H. Rosenlof (1999), Transport into the Northern Hemisphere lowermost stratosphere revealed by in situ tracer measurements, J. Geophys. Res., 104, 26,565-26,580.

Ridley, B., et al. (2004), Florida thunderstorms: A faucet of reactive nitrogen to the upper troposphere, J. Geophys. Res., 109, D17305, doi:10.1029/2004JD004769.

Rosenlof, K. H., A. F. Tuck, K. K. Kelly, J. M. Russell III, and M. P. McCormick (1997), Hemispheric asymmetries in water vapor and inferences about transport in the lower stratosphere, J. Geophys. Res., 102, $13,213-13,234$

Salawitch, R. J., D. K. Weisenstein, L. J. Kovalenko, C. E. Sioris, P. O. Wennberg, K. Chance, M. K. W. Ko, and C. A. McLinden (2005), Sensitivity of ozone to bromine in the lower stratosphere, Geophys. Res. Lett., 32, L05811, doi:10.1029/2004GL021504.

Sprenger, M., and H. Wernli (2003), A northern hemispheric climatology of cross-tropopause exchange for the ERA15 time period (1979-1993), J. Geophys. Res., 108(D12), 8521, doi:10.1029/2002JD002636.

Stohl, A. (2001), A 1-year Lagrangian "climatology" of airstreams in the Northern Hemisphere troposphere and lowermost stratosphere, J. Geophys. Res., 106, 7263-7280.

Stohl, A., et al. (2003), Stratosphere-troposphere exchange: A review, and what we have learned from STACCATO, J. Geophys. Res., 108(D12), 8516, doi:10.1029/2002JD002490.

Vaughan, G., and C. Timmis (1998), Transport of near-tropopause air into the lower midlatitude stratosphere, Q. J. R. Meteorol. Soc., 124, 15591578 .

Wernli, H., and M. Bourqui (2002), A Lagrangian "1-year climatology" of (deep) cross-tropopause exchange in the extratropical Northern Hemisphere, J. Geophys. Res., 107(D2), 4021, doi:10.1029/2001JD000812.

G. Berthet, Laboratoire de Physique et Chimie de l'Environnement, CNRS, 3A Avenue de la Recherche Scientifique, F-45071 Orleans Cedex 2 , France. (gberthet@cnrs-orleans.fr)

J. G. Esler, Department of Mathematics, University College London, 25 Gower Street London, London WC1E 6BT, UK. (gavin@math.ucl.ac.uk)

P. H. Haynes, Department of Applied Mathematics and Theoretical Physics, University of Cambridge, Cambridge CB3 0WA, UK. (p.h.haynes@damtp.cam.ac.uk) 